University of Nebraska - Lincoln

DigitalCommons@University of Nebraska - Lincoln

$1-1-1985$

\title{
Effects of Interpersonal Problem-Solving Training With Chronic Aftercare Patients on Problem-Solving Component Skills and Effectiveness of Solutions
}

\author{
David J. Hansen \\ University of Mississippi, dhansen1@unl.edu \\ Janet S. St. Lawrence \\ University of Mississippi \\ Karen A. Christoff \\ University of Mississippi
}

Follow this and additional works at: https://digitalcommons.unl.edu/psychfacpub

Part of the Psychiatry and Psychology Commons

Hansen, David J.; St. Lawrence, Janet S.; and Christoff, Karen A., "Effects of Interpersonal Problem-Solving Training With Chronic Aftercare Patients on Problem-Solving Component Skills and Effectiveness of Solutions" (1985). Faculty Publications, Department of Psychology. 309.

https://digitalcommons.unl.edu/psychfacpub/309

This Article is brought to you for free and open access by the Psychology, Department of at DigitalCommons@University of Nebraska - Lincoln. It has been accepted for inclusion in Faculty Publications, Department of Psychology by an authorized administrator of DigitalCommons@University of Nebraska - Lincoln. 


\title{
Effects of Interpersonal Problem-Solving Training With Chronic Aftercare Patients on Problem-Solving Component Skills and Effectiveness of Solutions
}

\author{
David J. Hansen, Janet S. St. Lawrence, and Karen A. Christoff \\ University of Mississippi
}

\begin{abstract}
Seven chronic psychiatric patients who were enrolled in a partial-hospitalization program and had difficulty solving interpersonal problems received group skills training. A multiple-baseline design was used to demonstrate training effectiveness through improved problem solving on trained situations and through skill generalization to novel, untrained situations. Maintenance of the training was evaluated after 1 month and 4 months. Social validation was accomplished by comparing the problem-solving competency of the patient sample with skills demonstrated by "normal" nonpsychiatric persons in their community.
\end{abstract}

Typically, formerly hospitalized psychiatric patients have poorer social networks and fewer intimate relationships than do individuals who have never been hospitalized for psychiatric treatment (Froland, Brodsky, Olson, \& Stewart, 1979). Recently, Mitchell (1982) reported that interpersonal problem solving is positively and significantly related to the number of close friendships and the degree of family support available to former patients. Because lack of social supports may result in poor readjustment in the community and increased readmission rates to inpatient settings (Phillips, 1968; Zigler \& Phillips, 1962), it appears important to equip psychiatric patients with problem-solving competencies that they can use in their everyday interactions following discharge and that may help them establish appropriate social networks.

To some extent, problem-solving skill deficits may be the result of living in institutional

The authors express their appreciation to Michael D. Roberts, director of the Region II Mental Health Center, Oxford, Mississippi, for his cooperation and his critique of an earlier draft of the article and to Joan Hill, program director for the Positive Living Center, a partial-hospitalization program affiliated with the mental health center. The authors thank Allyn Mitchell, Kilby Moore, Shirley Engle, and Cathy Goodwin for their valuable assistance and Jeffrey A. Kelly and Mark D. Mosk for their critiques of an earlier version of the article.

Corresponding author: Janet S. St. Lawrence, Department of Psychology, University of Mississippi, Oxford, Mississippi 38677 settings that promote passivity and excessively dependent behavior (Kelly \& Lamparski, in press). Current therapeutic strategies are based on the assumption that the ability to recognize and resolve everyday problems will contribute to lower recidivism rates and better adjustment in the community, and several studies support the assumption that such abilities do, in fact, have a bearing on successful community adjustment (e.g., D'Zurilla \& Goldfried, 1971; Froland et al., 1979; Liberman et al., 1984; Platt \& Spivack, 1972a, 1972b, 1972c, 1974; Spivack, 1973).

Although several investigators have recommended a social validational approach to clinical interventions (Christoff \& Kelly, in press; Holmes, Hansen, \& St. Lawrence, 1984), to date there are no published reports of problem-solving investigations that have assessed problemsolving competencies of individuals who are successfully living in the community and then trained psychiatric patients to approximate the criterion skills of these "normal" individuals. If the aim of clinical intervention is to teach disordered individuals the adaptive living skills used by successful individuals, then such social validation is critical. Recently, Holmes et al. (1984) used such a social validation approach for training former psychiatric patients in conversational skills. A similar approach can be adapted to interpersonal problem-solving training programs.

Social problem situations used in training should approximate actual situations that 
are problematic for the patient and that the patient is likely to encounter in the community. Problem-solving training has relied heavily on teaching responses to problem situations that clinicians have selected based on face validity and presumed relevance to actual situations that may be encountered. It is likely that training will be more effective if advance effort is expended to identify social situations that occur frequently and that are seriously problematic for the patients, a step that has not previously been introduced in the problem-solving literature.

A further pragmatic consideration is the need for group training programs that may be more cost-effective in applied settings than is individual treatment (Holmes et al., 1984; Kelly, 1982). Much of the existing research has involved expensive and time-demanding individual treatment, which may be in short supply in outpatient mental health settings where most chronic psychiatric patients receive treatment.

Finally, aftercare training may offer a distinct advantage promoting generalization and maintenance because patients have immediate opportunities to actually use the newly acquired skills as they reintegrate into the community. As yet, there have been no reports of empirically evaluated efforts to train aftercare patients in improved problem-solving competency because the existing literature has been derived from inpatient treatment settings.

The present study first assessed the problem-solving skills of nonpatient community volunteers and of formerly hospitalized psychiatric patients enrolled in a communitybased partial-hospitalization program. Problem situations selected for training were compiled over time from actual social situations that arose and proved difficult for a majority of the patient sample. The patients were then trained using a group training format without elaborate equipment. The effectiveness of training was evaluated by objectively rating patients' solutions to trained problem situations, as well as their handling of unfamiliar generalization situations. Maintenance of improved problem-solving competency was evaluated 1 month and 4 months following the conclusion of training.

\section{Method}

\section{Subjects}

Subjects were seven patients enrolled in a partialhospitalization program serving formerly hospitalized psychiatric patients at a regional mental health center. There were 5 women and 2 men, ranging in age from 24 to 45 years old ( $M=35.0$ years old). Subjects' educational levels ranged from third grade through 2 years of college ( $M=11.5$ years). None of the subjects were employed. Subjects' diagnoses (American Psychiatric Association, 1980) were determined by the partial-hospitalization director from information obtained through interviews with clients and family members and from hospital and mental health center records. Diagnoses were chronic undifferentiated schizophrenia $(n=5)$, paranoid schizophrenia $(n=1)$, and recurrent major depressive disorder $(n=1)$. All subjects were receiving antipsychotic medication (e.g., haloperidol or chlorpromazine), and 4 subjects were also receiving antidepressant medication (e.g., amitryptylene or imiprimine). Number of psychiatric hospitalizations ranged from one to two $(M=1.4)$, and total length of hospitalization ranged from 2 months to 44 months ( $M=11.9$ months). At the time the study began, length of participation in the partial-hospitalization program ranged from 2 months to 25 months $(M=10.9$ months $)$.

Subjects were referred for problem-solving training by the program's director after having been identified by the staff as deficient in adaptive problem-solving skills. For example, program staff cited the example of 1 patient who received an overdue notice from the power company. Although the client had previously paid the bill and had a record of payment in her checkbook, she took no action. As a result, her power was cut off, and she incurred additional expense to have it restored. More effective problem-solving skill could have allowed her to resolve the problem simply and without the interruption of service.

\section{Problematic Situations}

A pool of 57 narratives was generated from situations reported as problematic by the participants and program staff; scenes were also adapted from existing problem-solving literature (Edelstein, Couture, Cray, Dickens, \& Lusebrink, 1980; Platt \& Spivack, 1977). Due to the low reading skill of some subjects, the problem situation narratives were read aloud. To establish which situations were most problematic and relevant, each subject was asked, "Have you ever been in a situation like this?" and "Would it be hard for you to figure out what to do in this situation?" Dichotomous yes or no responses were recorded. The number of yes responses was divided by the total number of responses (yes responses plus no responses) to establish a relevancy/difficulty index for each situation. Twenty-two situations received a relevancy/difficulty index score of greater than $.50(M=.69 ; S D=.14)$, indicating each situation had actually happened to or was a problem for at least half of the subjects. These 22 situations were retained 
for training and generalization assessment. ${ }^{1}$ Four of the 22 situations were randomly chosen for training, and the remaining 18 situations were used to assess skill generalization. The following is a sample problem situation:

Your monthly check is delivered to your mailbox on the first of the month. You are at PLC (the partial-hospitalization program) when the check is delivered. Many of your neighbors have had their checks stolen recently, and your check was stolen last month. It is very timeconsuming and inconvenient to file for a lost check.

\section{Problem-Solving Components}

Five problem-solving skills adapted from Christoff et al. (1984) were chosen as dependent measures. Responses to each problem-solving situation were audiotape-recorded and later rated dichotomously for the occurrence or nonoccurrence of each component. Operational definitions of each component are as follows: problem identification - a specific statement of the problem; goal definition - a specific statement of the desired end; solution evaluation - a specific benefit or cost statement regarding the solution; evaluation of alternativesa specific benefit and/or cost statement regarding at least two solutions; and selection of a best solution - explicit choice of one of the proposed solutions as the best course of action. This could only be scored as an occurrence if more than one solution was generated.

In addition, solutions were rated for effectiveness using a 9-point Likert-type scale, ranging from very poor (1) to excellent (9). This measure was a rater's subjective evaluation of the solution's overall quality (i.e., the solution's relevance to the problem and how well the raters believed it would work).

\section{Problem-Solving Training}

Training was conducted using a group format. The research design was a multiple-baseline across skill behaviors design. Skill components targeted for training were problem identification, goal definition, solution evaluation, evaluation of alternatives, and selection of a best solution. Sessions were conducted twice weekly at the partial-hospitalization center by an advanced graduate student in clinical psychology. One skill component was trained until subjects demonstrated skill acquisition; then training progressed to the next skill component. Training procedures consisted of instruction and skill rationale, modeling, behavior rehearsal, feedback, and verbal reinforcement. Each session began with the therapist providing instructions and a rationale for the component to be trained. The therapist then modeled use of the skill, and each subject demonstrated use of the skill component to the group in the practice of one of the training situations. Corrective feedback and praise were provided by the therapist.

Assessment of training effects. Immediately after each training session, subjects were individually assessed on the four training situations and two situations randomly chosen each day for each subject from the pool of 18 generalization situations. Over the course of the study, subjects received some generalization situations more than once. The experimenter read each situation aloud and then asked, "How would you figure out what to do, and what would you do?" Responses were audiotaped and later rated by trained research assistants for overall effectiveness as well as for each of the problem-solving component skills.

Assessment of skill maintenance. One month and again 4 months following the conclusion of training, problem-solving skill was reassessed at the partialhospitalization center. The assessment procedure was the same, and no training occurred during the followup assessment sessions. All 7 subjects were enrolled in the partial-hospitalization program at the time of the 1month follow-up, and 6 remained at the 4-month follow-up session.

\section{Social Validation}

The social validation sample consisted of 20 adult volunteers recruited from the same community in which the patients resided. There were 14 women and 6 men, ranging in age from 22 to 60 years old $(M=33.9$ years old). Educational levels ranged from the eighth grade through a bachelor's degree $(M=13.8$ years $)$. The social validation sample and the subjects were not significantly different in age and educational level. Social validation volunteers were recruited in a convenience store, a laundromat, an insurance agency, offices, and other community locations. None had ever been a psychiatric inpatient.

Each person in the normative sample was assessed individually on the same narrative situations used for training the patient sample. Assessment of the social validation sample's problem-solving abilities took place in the community setting where each subject was recruited, and the assessment procedures were identical with those used with the subjects.

Prior to training, patients in the partial-hospitalization program scored significantly lower than did the social validation sample on the average effectiveness of their problem-solving solutions, $t(25)=2.42, p<.05$, providing further validation of the subjects' initial deficits in interpersonal problem-solving skill.

\section{Interrater Reliability}

Two raters independently rated the audiotaped responses, overlapping on $34 \%$ of the tapes randomly chosen from baseline, training, and follow-up assessments. Phi correlation coefficients for interrater reliability on each of the five component skills ranged from .77 to .94 . The Pearson product-moment correlation coefficient for interrater reliability on the rating of overall effectiveness was .79. Thus, the problem-solving component skills and overall effectiveness were reliably assessed.

\footnotetext{
${ }^{1}$ The problem situations are available from the second author upon request. Send requests to Janet S. St. Lawrence, Department of Psychology, University of Mississippi, University, Mississippi 38677.
} 


\section{Results}

\section{Problem-Solving Training Effects}

The percentages of situations in which each of the target skills occurred across baseline, treatment, and follow-up phases are presented in Figure 1. Each of the five component skills remained consistently near zero throughout its baseline phase for both the trained and the unfamiliar generalization situations. During baseline, subjects were almost never able to identify the core problem or to define a desired outcome. Furthermore, subjects rarely evaluated the effectiveness of their solutions or examined alternatives. Because subjects did not evaluate alternatives, it is not surprising that they did not proceed to a best solution.

Each component skill was rapidly modified with the introduction of treatment, and the improvement generalized to untrained situations. The pattern in the data is extremely clear. These changes always occurred at the precise time when their group training specifically focused on a skill component, demonstrating that subjects' behavior change was a direct result of their problem-solving training and that training generalized to unfamiliar problem situations. This evidence of systematic improvement clearly meets the treatment outcome criteria for the multiple-baseline design. Figure 1 also shows that by the 1-month follow-up assessment, subjects evidenced a decrement in each component skill for training and generalization situations. Further reductions were reflected by the 4-month follow-up data.

A $4 \times 2$ repeated measures analysis of variance (ANOVA) was computed for each component skill in addition to the graphical examination of the data. The two within-groups factors were training phase (baseline, training, 1-month follow-up, and 4-month follow-up) and situation (trained vs. generalization). Results of the repeated measures ANOVA $s$ are presented in Table 1.

The main effect for treatment phase was significant for each component. Post hoc Duncan's analyses were used to assess significant differences in the component skills across phases. Each component skill was significantly greater during its training phase than at base- line $(d f=24, p<.05$, for each and all subsequent comparisons). By the 1-month follow-up, improvement over baseline remained significant for three components: problem identification, goal definition, and selection of a best solution. By the time of the 4-month follow-up, improvement over baseline remained significant for problem identification and goal definition. Training phase data were significantly higher than 1-and 4-month follow-up data only for the component of solution evaluation. Oneand 4-month follow-up data were not significantly different for any component, indicating that the reductions evidenced on the graphical data were not statistically significant.

Comparisons of the training and generalization situations were significantly different for only two of the components: solution evaluation and evaluation of alternatives. For both, skills were significantly higher on the trained situations than on the unfamiliar generalization situations. Skill usage was equivalent on trained and untrained problem situations for the remaining three component skills.

Training Phase $\times$ Situation interactions were not significant for any component.

\section{Overall Effectiveness}

Mean ratings of the overall effectiveness of the problem-solving solutions for each session are presented in Figure 2. Solutions to both training and generalization situations improved over time; the largest increase occurred during the solution evaluation phase. Inspection of Figure 2 indicates that improvement was maintained at 1-month follow-up but slightly decreased by 4-month follow-up. To further evaluate the impact of training on overall effectiveness of solutions, an $8 \times 2$ repeated measure ANOVA was conducted. The two within-groups factors were phase (baseline, problem identification, goal definition, solution evaluation, evaluation of alternatives, selection of a best solution, 1-month follow-up, and 4-month follow-up) and situation (training vs. generalization). The main effect for phase was significant, $F(7,42)=5.16, p<.001$, indicating that there were significant differences in the ratings over time. The main effect for situation and the Phase $\times$ Situation interaction were 


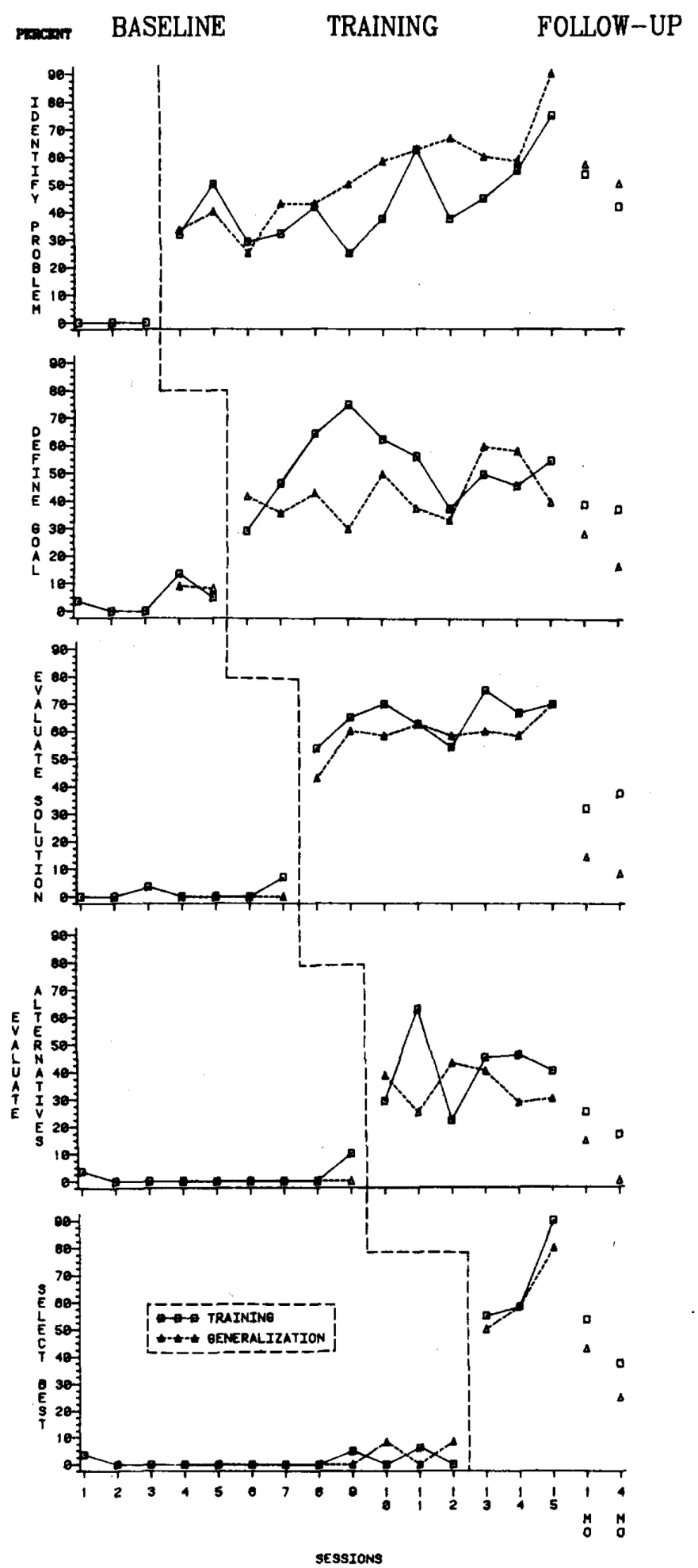

Figure 1. Mean percentage of occurrence of each problem-solving skill component by session 
Table 1. Repeated Measures Analyses of Variance for Problem-Solving Component Skills

Situation (trained vs.

\begin{tabular}{|c|c|c|c|c|}
\hline \multirow{2}{*}{$\begin{array}{l}\text { Problem } \\
\text { solving skill } \\
\text { component }\end{array}$} & \multicolumn{2}{|c|}{ Training phase } & \multicolumn{2}{|c|}{ generalization) } \\
\hline & $F(3,18)$ & $p<$ & $F(1,6)$ & $p<$ \\
\hline $\begin{array}{l}\text { Problem } \\
\text { identification }\end{array}$ & n 10.52 & .001 & $n s$ & \\
\hline $\begin{array}{l}\text { Goal definition } \\
\text { Solution }\end{array}$ & 7.56 & .01 & $n s$ & \\
\hline evaluation & 9.01 & .001 & 8.29 & .05 \\
\hline $\begin{array}{l}\text { Evaluation of } \\
\text { alternatives }\end{array}$ & 3.95 & .05 & 9.13 & .05 \\
\hline $\begin{array}{l}\text { Selection of } \\
\text { best solution }\end{array}$ & 7.77 & .01 & $n s$ & \\
\hline
\end{tabular}

Note. Training Phase $\times$ Situation interactions were not significant for any component.

not significant. Thus, the effectiveness of subjects' solutions to generalization situations did not significantly differ from solutions to training situations, which indicates training effects generalized to untrained situations.

Post hoc Duncan analyses were computed to evaluate the differences in overall effectiveness ratings between phases. Baseline did not significantly differ from the first three training phases (problem identification, goal definition, and solution evaluation). Baseline, problem identification, goal definition, and solution evaluation were significantly lower than the last two training phases (evaluation of alternatives and selection of a best solution) and 1-month follow-up $(d f=48, p<.05$, for each comparison). Evaluation of alternatives, selection of a best solution, and 1-month follow-up did not significantly differ from each other. Ratings at 4-month followup were not as low as during the early phases or as high as later phases and as a result did not significantly differ from any other phase. Thus, by the evaluation of alternatives phase and through 1-month follow-up, ratings of overall effectiveness were significantly greater than at baseline, and a nonsignificant decrease was obtained at 4-month follow-up.

\section{Social Validation}

Ratings of the overall effectiveness of problem-solving solutions for both the social validation sample and the subjects are contained in Figure 2. The dotted line that extends from

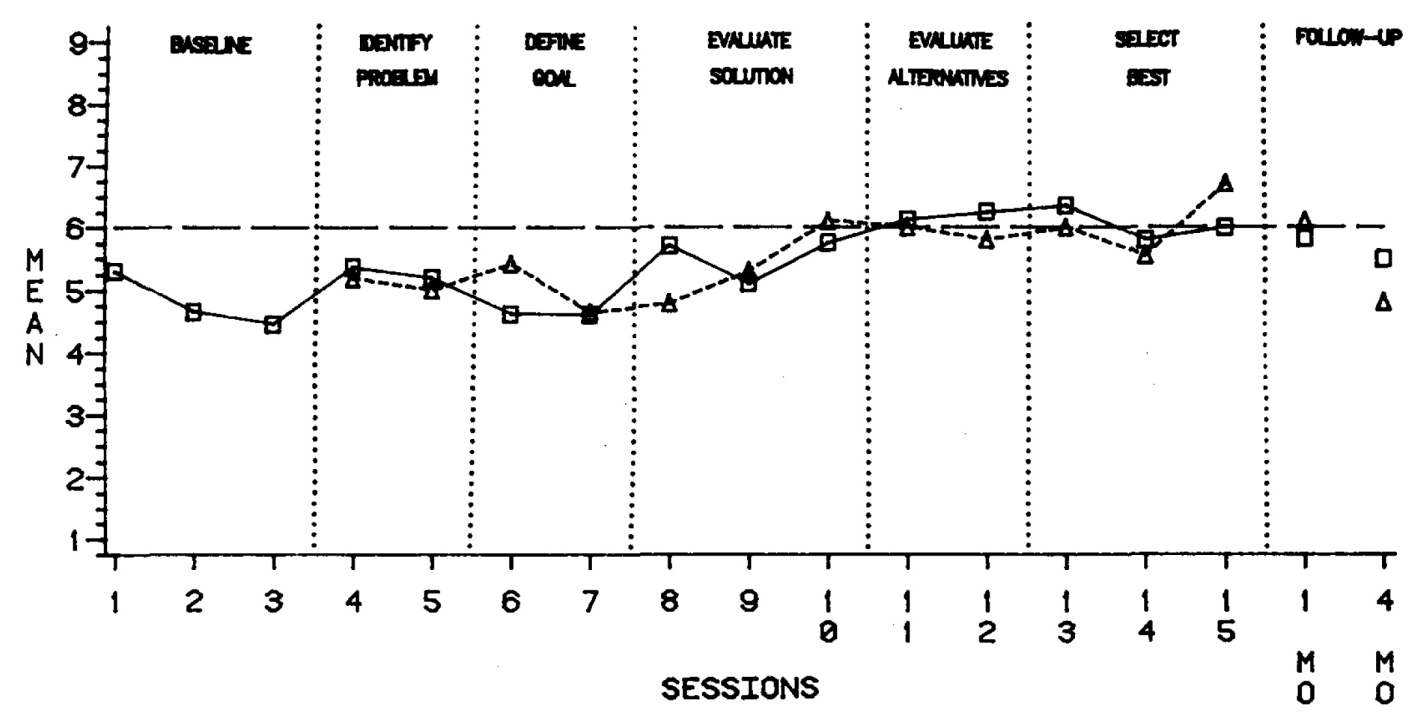

$\because$ TRAINING

Figure 2. Mean ratings of overall effectiveness of problem solutions by session. (The dotted line extending from the vertical axis indicates the mean for the normal nonpatient social validation sample. Ratings range from very poor [1] to excellent [9].) 
the vertical axis indicates the mean ratings for the nonpsychiatric social validation sample of community volunteers. Prior to training and through the first three training phases, subjects' problem-solving effectiveness was significantly lower than that of the social validation sample on trained situations: for baseline, $t(162)=3.69, p<.001$; for problem identification, $t(134)=1.99, p<.05$; for goal definition, $t(134)=3.90, p<.001$; and for solution evaluation, $t(162)=2.79, p<.01$. Similarly, on the generalization situations, subjects' ratings were also significantly lower than those for the social validation sample through the first three phases of training: for problem identification, $t(106)=$ $2.07, p<.05$; for goal definition, $t(106)=2.18$, $p<.05$; and for solution evaluation, $t(120)=$ $2.78, p<.01$. During the last two phases of training and during the follow-up assessments, subjects no longer differed from the social validation sample in solution effectiveness either for trained or generalization situations. Thus, by the evaluation of alternatives phase of training, subjects had improved the effectiveness of their problem-solving solutions until they were equivalent to the sample of normal, nonpsychiatric individuals in their community. This improvement was maintained across the $1-$ and 4-month follow-ups for both trained and untrained problem situations.

\section{Discussion}

The present study demonstrated the effectiveness of group interpersonal problem-solving training with chronic aftercare psychiatric patients. Following training, the frequency of targeted problem-solving components increased substantially. Training effects generalized to unfamiliar problem situations and were largely maintained at 1- and 4-month followups. Furthermore, for both the trained and unfamiliar social problem situations, subjects' overall problem-solving skill at post-treatment and through follow-up was equivalent to the competency levels of individuals who were functional in the community. Given the very recalcitrant nature of chronic aftercare patients' maladjustment in the community, the gains reported here are very meaningful. The present study does not address the issue of improved social adjustment. Yet, the powerful nature of the treatment effects was clearly demonstrated by the fact that increases generalized to unfamiliar problems and reached socially validated competency levels.

By the time of the follow-up assessments, subjects' performance levels on individual component skills evidenced a decrement from posttreatment levels. This regression from posttreatment gains is a commonly observed phenomenon in social skills research (Andrasik \& Matson, in press). Several possible explanations are suggested. First, the skill decrements may reflect failure to maintain treatment gains. If so, the use of training techniques that facilitate skill maintenance warrants further exploration and may prove to be of considerable value when working with such chronically disturbed populations. A second interpretation can also be offered. Over time, it is possible that subjects internalized the problem-solving component skills and thus could successfully confront a problem situation without needing to verbalize the more laborious, step-by-step process. If so, their follow-up performance levels may even more successfully approximate normal individuals' problem-solving strategies because the social validation sample rarely articulated each distinct stage leading toward a problem's resolution but covertly reached appropriate conclusions. Such an interpretation is made more plausible because ratings of the patient and social validation samples' overall effectiveness of solutions remained equivalent at posttreatment and throughout the follow-up period, even though graphical representations of the individual components appear to evidence a decrement.

The current findings and literature to date do not empirically address the extent to which improved problem-solving skill will actually generalize to, and be reflected in, patients' actual behavior when they are confronted with problematic in vivo situations. The extent to which verbal knowledge of the problem-solving principles carries over to patients' behavior when addressing problems first hand is not yet fully clear because what persons say they would do in a situation and how they, in fact, behave may have little correspondence. It is clear that prob- 
lem solving cannot be trained or assessed in isolation and that an assessment of actual performance in real-life settings is essential for meaningful evaluation of clinical training. Despite anecdotal evidence of improved problemsolving competency, the research to date has not assessed social problem solving in vivo.

Thus, the present investigation does not provide direct evidence that problem-solving training has a direct impact on community adjustment, recidivism rates, or severity of illness. However, it suggests that such training improved subjects' ability to generate more effective verbal solutions to everyday problems. Although it would be tempting to suggest that recidivism improved for the trained patients simply because none have required rehospitalization for 24 months since training took place, there is no way, given the presently available data, to validate such a statement for this particular group of patients. This important issue clearly warrants further research effort.

\section{References}

American Psychiatric Association. (1980). Diagnostic and statistical manual of mental disorders (3rd ed.). Washington, DC: Author.

Andrasik, F., \& Matson, J. L. (in press). Social skills with the mentally retarded. In L.L'Abate \& M. A.Milan (Eds.), Handbook of social skills training and research. New York: Wiley.

Christoff, K. A., \& Kelly, J. A. (in press). Social skills training with psychiatric patients. In L.L'Abate \& M. A.Milan (Eds.), Handbook of social skills training and research. New York: Wiley.

Christoff, K. A., Scott, W. O. N., Kelley, M. L., Schlundt, D. A., Baer, G., \& Kelly, J. A. (1984). Social skills and problem-solving training for shy young adolescents. Manuscript submitted for publication.

D’Zurilla, T., \& Goldfried, M. (1971). Problem-solving and behavior modification. Journal of Abnormal Psychology, 78, 107-126.

Edelstein, B. A., Couture, E., Cray, M., Dickens, P., \& Lusebrink, N. (1980). Group training of problemsolving with psychiatric patients. In D.Upper \& S. M.Ross (Eds.), Behavioral group therapy, 1980: An annual review (pp. 85-102). Champaign, IL: Research Press.
Froland, C., Brodsky, G., Olson, M., \& Stewart, L. (1979). Social support and social adjustment: Implications for mental health professionals. Community Mental Health, 15, 32-93.

Holmes, M. R., Hansen, D. J., \& St. Lawrence, J. S. (1984). Conversational skills training with aftercare patients in the community: Social validation and generalization. Behavior Therapy, 15, 84-101.

Kelly, J. A. (1982). Social skills training: A practical guide for interventions. New York: Springer Publishing.

Kelly, J. A., \& Lamparski, D. M. (in press). Outpatient treatment of schizophrenics: Social skills and problem-solving training. In M.Hersen \& A. S.Bellack (Eds.), Handbook of clinical behavior therapy with adults. New York: Plenum Press.

Liberman, R. P., Lillie, F., Falloon, J. R. H., Harpin, R. E., Hutchinson, W., \& Stoute, B. (1984). Social skills training with relapsing schizophrenics: An experimental analysis. Behavior Modification, 8, 155-179.

Mitchell, R. E. (1982). Social networks and psychiatric clients: The personal and environmental context. American Journal of Community Psychology, 10, $387-401$.

Phillips, E. L. (1968). Achievement place: Token reinforcement procedures in a homestyle rehabilitation setting for "pre-delinquent" boys. Journal of Applied Behavior Analysis, 1, 213-223.

Platt, J. J., \& Spivack, G. (1972a). The content of problemsolving thinking in psychiatric patients and controls. Unpublished manuscript. Department of Mental Health Sciences, Hahnemann Medical College and Hospital, Philadelphia, PA.

Platt, J. J., \& Spivack, G. (1972b). Problem-solving thinking of psychiatric patients. Journal of Consulting and Clinical Psychology, 39, 148-151.

Platt, J. J., \& Spivack, G. (1972c). Social competence and effective problem-solving thinking in psychiatric patients. Journal of Clinical Psychology, 28, 3-5.

Platt, J. J., \& Spivack, G. (1974). Means of solving real life problems: Psychiatric patients versus controls and cross cultural comparisons of normal females. Journal of Community Psychology, 2, 45-48.

Platt, J. J., \& Spivack, G. (1977). Measures of interpersonal cognitive problem-solving for adults and adolescents. Unpublished manuscript.

Spivack, G. (1973). A conception of healthy human functioning. (Research and Evaluation Rep. No. 15). Philadelphia, PA: Hahnemann Medical College, Department of Mental Health Sciences, Division of Research and Evaluation.

Zigler, E., \& Phillips, L. (1962). Social competence and the process-reactive distinction in psychopathology. Journal of Abnormal and Social Psychology, 65, 215-222. 